\title{
The Cyborg Entity in Gibson’s Neuromancer: An Idealistic “Cyborg Manifesto?”
}

\author{
Sanyat Sattar \\ Jahangirnagar University, Dhaka, Bangladesh
}

\author{
Abu Saleh Md. Rafi \\ Daffodil International University, Dhaka, Bangladesh
}

\begin{abstract}
The idea of Cyborg initiates the blurring of frontiers between traditional gender roles in the post-modern era, transforming itself into a politicized entity. William Gibson's Neuromancer as an early introducer of the Cyborg characters tries to dissolve the boundaries through his female characters by balancing the power quota with the help of the non-gendered entity of the Cyborg. According to Donna Haraway, there will be a dawn of new cyborg era causing a gender role reversal. The objective of this paper is to find whether such role reversal is at all possible.
\end{abstract}

Keywords: cyborg, postmodern fiction, infotopia, posthuman, cyberfeminism, cyborg manifesto

\section{Introduction}

Cyberspace is a complex network of communications. The word "cyberspace” was coined by William Gibson in his novel Neuromancer. In Gibson's cyberspace, people live virtually by leaving their physical bodies. In that sense, Gibson's cyberspace is a combination of virtual simulation and the internet. Cyberspace as William Gibson describes is a "consensual hallucination" (Gibson, 1984, p. 1). Thus cyberspace helps to transgress gender boundaries.

Following the path of radicalism, feminism prophesizes a self-transformed future with the cyborg, in an attempt to find salvation from the claws of patriarchy - a genderless entity that holds the key to rise above the politics of the body. In creating a new equilibrium, a genderless entity seems to be most promising because a being without the question mark of gender, eliminates the body politics that was so long used to justify male domination. Donna Haraway, the most prominent feminist of the third wave feminism thus prophesizes about the cyborg entity in her essay "The Cyborg Manifesto". Here the manifesto seems to be an encrypted message for the women, which holds the promise of a new future where women will not be subjected to dominance rather they will hold the equal power to domination. So, in the near future, we might be submerging into the world of cybernetics and virtual reality. But this blending of the gender roles might still seem to be a distant future for certain solid reasons. Our point is, Haraway overlooks the politics of the gender and the body in the postmodern world. She miscalculates the prevalence of patriarchy ignoring the fact that gender-politics is dangerous on several levels. This not only creates room for politics, but also leaves no room for alternative/countermeasures. The reason that renders this prophecy as flawed is because Haraway takes an essentialist position, taking a side deliberately for one's own cause by underestimating the possible politics. Ignoring the possibility of the spawning of new kind of politics, Haraway takes the position of that of the 
optimistic feminist, which assumes that the entity of the cyborg is essentially feminist. In the process of creating an entity bearing no question (genderless), Haraway contradicts herself by taking a one-sided essential position with the cyborg. Thus her essential feminist position helps to give rise to newer gender politics, which will eventually put us once again in the dreaded loophole of gender struggles in this info-topia (information utopia). On the other hand, a genderless entity may create the ground for a posthuman identity crisis. This identity crisis might eventually create an all-out existential crisis, just like the post-war conditions of WWII. This identity crisis might lead to the essentiality of gender. That is why when we are talking about a post-gender world simply eliminating the factor of gender does not eliminate the factor of politics. Thus, as it was in the history of feminism, the post gender body becomes the site of discourse. This is what Haraway had failed to anticipate.

The idea that Haraway argues which will keep cyborg out of the reach of the politics of patriarchy is that cyborg is without any history. So, a being which is without any history or origin, does not supposedly have any gender tag with it, will be devoid of any complex (Oedipus or Electra), and will probably be able to rise above the politics of the body. According to Judith Butler, the boundaries of sex and gender cannot be so easily transcended. In her book Bodies That Matter: On the Discursive Limits of Sex (1993), she tries to explain the misconception of gender performativity. No matter what gender we might pick to perform, it is through the everyday practices of culture that we eventually follow a particular track of gender performativity. Iterability, an expression that Butler borrows from Derrida, is the repetition of cultural and social norms, which in itself creates a set of cultural norms for everyone to follow. So no matter what, as a social being we eventually get succumbed into the dominant heterosexual hegemony. Even though cyberspace or the internet has given the opportunity for the blurring of boundaries through virtual IDs (ID = Identification) but can we really transcend the boundaries even in the cyberspace? In the popular social networking sites the process of Iteration is very much prevalent. Through group activities, through group photos and for the virtual public commentary space created by these sites, everybody's gender orientation is molded to a certain path of performativity. Slavoj Žižek's second veil of "inter-subjectivity" can be remembered here because we become what others want us to become. As we post our group photos and activity on social networking sites for other people to comment on and see, we are influenced by their comments and the process of Iteration takes place. As the cyberspace has become the ground for many revolutions, it has provided feminism with women only spaces, but on the other hand in this age of virtual reality, it has also become a meeting place. So even though we are witnessing an era of postgenderism, gender in cyberspace does become an issue. Again, we are bound by the cultural Iteration. Cultural iteration is the act of becoming habituated with certain activities by the constant repetition and performance of those activities. That is why, as we fail to truly transcend to the concept of postgenderism, cyborg is maybe without history but not without culture. Rising above the politics of culture proves to be our biggest challenge yet, thus rising above the politics of the body seems to be far-fetched.

\section{Data Body Versus Posthuman}

We live in an age of information utopia where information is available to anyone and has become an indispensable part of our lives. In the info-topia (Informational Utopia), data is the currency of exchange. Continuously what we are exchanging to get our way through this infinite cyberspace is data. That is why Arthur Kroker has termed the post-modern, post-human body as the "Data Body". According to Kroker, we are continuously emanating data from our bodies, from the most basic data like gender and sex to more complex 
data such as personality. For this reason, a body can never be known without its data. Hence, without the data emanating from our bodies which might the case with post-gender, it might become impossible for a body to survive as data is the life blood of the post-modern world. This concept contradicts Katherine Hayles's idea of the post-human. In her book How We Became Posthuman (1999), she describes how the data lost its body. As data has lost its body, now it is possible for humans to transcend the boundary of the physical and enter the non-physical virtual world as post human. But she is unsure of the possibility that how a human brain can be fully transformed into data with all its complex neurological and electromagnetic functions. Will data define the body or will it leave its host-we will let future be the judge of that but for now we can reach a denotation that in this info-topia we can exist without being Data Bodies because information is data.

In eco-feminism, there was an attempt to take women back to nature in trying to compare them with feminine entities like mother earth who is naturally good and docile. Women were compared to embodied entities like nature and men were compared to disembodied entities like culture. Men as disembodies entities held the politics and women as nature became the subject of politics because nature is always dominated by culture. Thus the female body itself becomes the ground for discourse and patriarchic politics. As cyborg is devoid of history but not culture, it brings back the nature versus culture dualism and the dominance of patriarchy. Women as embodied entities, as data bodies, will continue to remain as the subject of patriarchal dominance. As data remains of utmost importance in explaining the identity of the body, so does patriarchal politics. The continuous production of data from our bodies creates our identity and our identity is related to our gender and as long as we are gendered there will be body politics because post-gender itself is a gender.

\section{Neuromancer and Cyberfeminism}

The celebration and the realization of the post-gender had originally begun from the SF (Science Fiction) novels. During the 1970s and 1980s technology was thought as masculine, hence the term boys toys. It is only after the works of many feminist theorists that the SF genre started to change to accommodate the women readers also. William Gibson's Neuromancer is one of the first groundbreaking novels that had celebrated feminism and women, to be more specific.

Sadie Plant in her book Zeroes+Ones posits optimism about the subversive potential of the internet that could potentially transform the life experience of the women. She starts by deconstructing the binary language that is used in programming and asserts that the binary coding language itself has the potential to offer itself to the females. She argues that in the binary codes the "zero" is essentially female and the "one" constitutes the male phallic order. She holds that in the nonlinear world of cybernetics, the zeroes are displacing the phallic ones indicating a digital future, which is essentially feminine. Thus, starting from the coding language of the cyberspace itself, the digital future holds infinite possibilities for women. With the advancement of the internet, it has created new potentials for feminism, hence cyberfeminism. Cyberfeminism developed individually because internet has the potency to create private and public spaces for everyone. Internet is a unifying entity, which can unify women of all classes into a common space. Though the question of colored and third world women being subsided surface, internet opens up space for everyone in a unity of sisterhood. Marching in the roads with festoons and placards demanding equal rights have become a thing of the past. Now there are movements occurring online. These are known as ISMs or Internet Social Movements. There are also blogs, online communities, and social networks, which constitute and contribute to these movements-movements such as the issue regarding the black subaltern women. Also the cyborg entity creates the conditions of 
postmodern and postgender which eventually helps women to transcend their so called "biological" constraints. No other novel addresses these technological advancements in celebrating women other than William Gibson's Neuromancer. Through advanced body augmentations Gibson's characters do help to create a cyborg future and at the same time the bodiless exaltation of the cyberspace enables one to leave one's body behind, thus escaping the prison of one's own body to transcend beyond boundaries of gender and sex-moving beyond the physical, places brain over brawn, creating an even ground for everyone because the mind has the power to transcend physical limitations. If we are talking about postmodern transcendence then its transcendence is from the physical, from gender, and from dominance. At the same time this transcendence is not metaphysical rather it has a material manifestation, which means this transcendence is palpable and possible. The celebration of the cyborg future is evident if we observe one of the main characters of the novel, Molly. Molly is what the third wave feminism is all about. By assuming the position of a cyborg, she initiates the gender role reversal in Gibson's dystopian infotopia, but not entirely fulfilling Haraway’s proposition.

\section{Molly: The Razor Girl}

William Gibson's character Molly Millions is rough and tough and in command of the male characters of the novel Neuromancer. She is independent and very ruthless. Thus by familiarizing herself with the attitudes and behaviors that were once allotted to masculinity, she is walking along the path that Donna Haraway assumed. With advanced prosthetics and body augmentations, Molly has been stripped off from her feminine attributes and sores beyond the two normative gender identities. This newborn entity and the vagueness surrounding this entity provide cyborg with an edge because the failure to grasp and understand this entity creates a sense of fear. This fear adds cyborg with the power to overturn the power relations. Thus Molly becomes the lethal "razor girl" who acts as the muscle of all the operations conducted in Neuromancer. She commands the ruthless Panther Moderns whom she uses to hack into the Sense/Net and steal the construct of Dixie Flatline. She is the main ground operative for the invasion of the Villa Straylight. Among her body enhancements there are, silver eye cover implants, heightened neural response, a digital visual read out and most shocking of all improvements is the retractable razor blades beneath her burgundy nails. Thus she becomes the manifestation of Freddy Krueger from A Nightmare on Elm Street (1984), but only this time she becomes the nightmare for patriarchy. Sneering remarks on gender are no longer an issue to sit quiet upon, which we see when Teribashjian makes a sexist comment on Molly regarding being a woman, Molly instantly replies that if he had made such comments again he would need to pay appallingly. Molly and Reveira both have dangerous body augmentations. Reveiera can project images with his eyes. They both represent the second stage or condition of Baudrillard's simulation, which is Simulacra mask and perverts the basic form of reality. Molly being a cyborg, her obvious resemblance to simulacra is evident and Reveira with his ability to create and project a distorted reality into anybody's mind is his ability to pervert and hide the reality. It is this that is created by technology. In my sense, it has a positive aspect. Because by escaping the real through technology and the real, where patriarchy had ruled, this distortion allows for a subversive resistance against patriarchy. For her expensive body augmentations, Molly had to work as a "meat puppet". Third wave feminism celebrates the female body, where the female body is considered as assets and using/showing such assets is no longer matter of shame or disgrace. Rather it is possible for women to use her body as a site of resistance. That is what Molly does to bring about her change and break the shackles of patriarchy. It is not only considered that women are biologically inferior but also too much emotional in the cognitive aspect of the 
body. Thus Molly's body augmentations enable her to get rid of her emotions: “I don’t cry, much” "But how would you cry, if someone made you cry?" "I spit [Molly] said” "The ducts are routed back into my mouth" (Gibson, 1984, p. 119). Through her augmentations, Gibson strips Molly from any kind of emotions, turning her more masculine. Thus Molly not only strips off her feminine identity, but also forms a new one, which is more masculine and at the same time individualistic. Her body enhancements along with cyberspace, too provide us with ability to shift our identities. This identity shift enables us to cross gender and body boundaries. Lisa Nakamura in her book Cybertypes first coined the word "identity tourism". This simply means that members of a particular group try on the identity of another group with different race or gender. Nowadays, anyone can have multiple internet profiles without having to know what that person's gender is. This opportunity has opened up space for transvestite or cross dressers because in real life a person wearing another gender's clothes is considered socially unacceptable. Cyberspace opens up the space for living in the identity of another gender. Thus Molly, who is a street samurai in real life, is also the commander in charge inside the Matrix. Matrix is the simulated virtual cyberspace in William Gibson's Neuromancer where everybody “jack-in” leaving their bodies to enter that cyberspace only using their minds. For her advanced body augmentations, she is a lethal character to trade with in real life and inside the Matrix, where the cyberspace helps her fully leave her gender identity. She also passes through the test of endurance. When in their last run in the Villa Straylight, Molly is critically injured. Though with her wounds, she carries on with her mission. At that time, it was only Henry Dorsett Case who was linked to her through simstim, could feel what sort of pain Molly was going through at that time. Even with that pain Molly does not give in to her pain and makes the mission a success. Thus by overcoming barriers of power, sense perception, emotion, and endurance, Molly is able to escape her previously considered weak body. Molly was so bent on overcoming these barriers to improve her dominated condition to become an independent cyborg that she was not afraid to work even as a meat puppet. That is why Molly is the representation of third wave feminism in its most radical form. But is this portrayal entirely the ideal "Cyborg Manifesto", which is still yet to be answered.

\section{The Passive Case}

Neuromancer revolves around Henry Dorsett Case. Though Case is the protagonist, Molly takes much of the action and Case is rendered to an "antihero". So, instead of taking control of the actions, his actions are taken by others, namely, Molly: "For a few frightened seconds [Case] fought helplessly to control Molly's body. Then he willed himself to passivity became the passenger behind her eyes” (Gibson, 1984, p. 39). The name Case might indicate the case or chassis of a computer. Case is just a shell of a man who does not take any actions rather than follows Molly's lead and feels what she feels through simstim. Even sexually Case does not remain in the dominant position rather Molly takes control and initiates the erotic endeavor in the Coffin hotel by herself. Maybe Case was an action taker when he was a freelancing console cowboy till whom he used to work for, the Russians, disabled him from "jacking in" to the Matrix. This can be another reason that because of his disability he thinks that he has been imprisoned inside his own body. Thus in order to take action, the only way left for him is the cyberspace or the Matrix. He cannot take action in real life because Molly is in control of the operations and Case is working under her. In order to prove his prowess and worth, he must escape to the cyberspace to attempt becoming a posthuman wetware. According to Lennard J. Davis, the enforced normalcy of not being able to log into the cyberspace renders Case an anti-hero. Davis also talks about the capitalistic era where workers not having a perfect body for work or in this story "Case's inability to log in”, 
is a stigma - a stigma that Case wants to remove at any cost even if it means working for the bad guys. Case also has body augmentations but rather than improving his abilities they work to decrease Case's abilities. Case has toxin sacks planted inside his body which will melt if he tries to double cross his employers and he has his pancreas removed, so that he cannot reach the hallucinated state of the drugs. Thus agreeing with Jacques Lacan, which Lennard J. Davis uses in his book Enforcing Normalcy: Disability, Deafness and the Body, Case might be trying to make his fragmented disabled body whole and the only way to do this is to leave his fleshy body and escape into the cyberspace. There might be another thing, which might provide him with sense of wholeness and that is drugs. Thus in the end of the story when Case comes face to face with Linda Lee resurrected by Neuromancer in cyberspace, he is able to wake up from that "Mummified state of immortality" (Case's mind would remain in the cyberspace as a construct) only when the Rastafarian Maelcum injects Case with a drug strong enough that would work instead of his disabilities. The drug probably gave him the sense of wholeness outside cyberspace. Thus with all his disabilities, Case remains as an antihero leaving actions to be taken by Molly.

\section{Smoldering Flame of the Beat}

The Beat Generation starting from the post WWII period provided a deviation from traditional thinking patterns. They were bringing innovation to style, experimented with drugs, alternative sexualities and showed a great deal of interest in Eastern religions. The things that they were doing provided unorthodox ground breaking practices; especially creating a ground for the women. That is why William Gibson's Neuromancer got such popularity among the Beat Generation, because it supported the counter culture movement of the Beat Generation. Many of the terms from Neuromancer started to be used in daily lives. Beat was popular among all sexes because it supported radical feminism. Experimentation with drugs was done in hope of transcendence or more likely to have the feeling of disembodiment. Ecofeminism tried to portray women as embodied entities and men as disembodied entities. The problem of such dichotomy is that the embodied entities can be stigmatized but the disembodied entities remain aloof and become more philosophical. Thus, if women had to be free they had to escape embodiment. Hence, Haraway's cyborg, which creates a new entity, is a hybrid, which is better than the two normative genders. Internet or cyberspace provides that opportunity for disembodiment, just like in Neuromancer where people can connect into the cyberspace where they can be disembodied and that space levels the ground for gender struggle. Recalling Virginia Wolf's A Room of One's Own, Nouraie Simone describes cyber space as a "liberating territory of one’s own” (Daniels, 2009, p. 109). She describes cyberspace as a place of resistance. It is a place where it is possible to discuss gender politics, feminism, or patriarchy and she states that it is possible for women to discuss this matter more intimately and on a personal level. According to Simone, cyberspace becomes a liberating space for many women just like Molly Millions in Neuromancer. Addressing the issue of violence against women online becomes a safer ground to address and make arguments about such sensitive matters. Thus cyberspace is safer for women than real life. In the race to become cyborgs, another issue that needs to be addressed is the issue of body invasion. The technologies that we are using and going to use are invading our bodies. For better or worse, technologies will be invading but it's our choice whether we use it for greater good or for criminal activities that's up to us. Like everything else, technology too has its pros and cons. Here Gibson trades carefully in excluding the negative connotations of body invasion. Gibson wants to show that body invasion is positive and welcomes the technologies to invade us because this is what he also thinks will liberate women for the greater good. Cyborg 
ushers the era of a paradigm shift—a shift that George Orwell talked about regarding the government he portrayed in his novel Nineteen Eighty-Four (1949).

\section{The Sex-Thing}

Though Molly Millions from Neuromancer is a very independent and strong woman, there is a stigma attached to her also. She has advanced body augmentations, which allow her to cross her gender limitations. But how did she pay for her expensive prosthetics? As referred previously, being a "meat puppet”. A meat puppet is a prostitute in William Gibson's postmodern world. As the name suggests the meat is only valuable and thus she is made unconscious when renting herself to her customers by just being a chunk of meat. Hence her customers can use her body anyway they want in an attempt to fulfill their necromantic snuff perverseness. So the question comes that, though Molly has become the independent dangerous street samurai by doing prostitution, is she really free from patriarchy? The answer is NO. She has rather become a victim of the informatics of domination. She did it because to begin with she herself being a woman was in a dominated state. Molly with her will to be liberated from her compromised position had to attempt to become a technologically advance cyborg. Her will to become a cyborg lies might be in the thought that technology would help her to overcome her biological deficiencies, as because she later became a street samurai and a body guard. To have those expensive body augmentations, she needed money as they are expensive and to make quick money there are few better ways than prostitution. Thus she falls in the circuit of the informatics of domination. Third wave feminism celebrates the sexual freedom of women. By using this concept of sexual freedom, patriarchy forces women into willing submission to male urges with the informatics of domination. Molly herself comes to hate her past self when she was used as a snuff doll because whatever the price is, that degrading position is not worth it.

\section{Sensual Cyberspace and the Female Rollercoaster}

Cyberspace by William Gibson has been described as a “consensual hallucination” (Gibson, 1984, p. 1). Virtual reality offers that sensual experience. Virtual reality being immersed in a world, which is the simulation of the real world, can let anyone have their wildest dreams come true. This has also become a site of suppression for women. As the commercialization of cyberspace is made so is the sex industry taking over the virtual world. It is now possible to have the experience of real sex through sex simulation games. Virtual reality thus becomes essentially a place controlled by patriarchy. As virtual reality is sensual, viewers can see, touch, feel, and smell. Thus Baudrillard's conception of simulation comes true as the line between real and the unreal gets blurred because virtual reality becomes more than real. Joseph Lanza in his essay "Female Rollercoasters" compares virtual reality with a coaster. He imagines a ride through virtual reality, which would provide an ecstasy of riding a female. Before that he deconstructs the rollercoaster. The classic roller coaster from the beginning of the 20th century was very simple with a few ups and downs and a few quick turns. Seen against the more masculine rides like the train which were faster and with straighter lines, rollercoaster was a symbol of woman. The coasters were named femme fatales. After the World War II with advancement in technology, they began to change. With aerodynamics coming into play, they were now loops and bigger thrilling drops. With the advancement in coaster even a simple ride like a rollercoaster began to hold gender politics. Joseph recognizes the loops as female breasts and the cork screws of sudden plunges are seen as phallic symbols. Thus as containing the politics of both genders the thrill of a rollercoaster became a postmodern gender bender. What 
got his most interest was a notion of Atari. According to Joseph, "My interest rekindled after reading a Time article about how Atari founder and cyberspace enthusiast Nolan Bushman 'eagerly foresees games in which people would not just play but actually be Ms. Pac-man”” (Lanza, 1992, p. 53). The concept of being and feeling the sensation of a woman can be achieved through virtual reality. This technology is present in Neuromancer and it is called simulated stimulation or in short "simstim". Through simstim, Henry Dorsett Case is connected to Molly. Case feels every bodily sensation that Molly has, but he is unable to respond because it is a one-way transmission. It's a one way transmission because it is a feeling system not a communication system. Now the question can be raised that is it not like the same technology she had when she was working as a meat puppet? This technology can be best described from the following words,

$[\mathrm{H}] \mathrm{e}$ heard the words and felt her from them. She slid a hand into her jacket, a fingertip circling a nipple under warm silk. The sensation made him catch his breath. She laughed. But the link was one way. He had no way to reply. (Gibson, 1984, p. 39)

Patriarchy has made technology masculine. Just like real life rollercoasters, Molly just becomes a ride for Case. It's a one-way ecstasy where Molly is the provider and Case is the receiver. Thus simstim/masculine technology holds the potential to subjugate women because "Travel into a time-space warp. Swim through your own birth canal and even be the woman giving birth to yourself. The thrill ride of the future is with us today. Let her entertain you!” (Lanza, 1992, p. 51).

Though Neuromancer celebrates feminism through Molly, what about the other female characters? Firstly, there are only a few female characters compared to the male characters in the novel. With these few number of women, the male characters almost all the time occupy the scenario. Secondly, though Molly is an independent strong girl, at the end of the novel she needs rescuing by Case like a damsel in distress. Thirdly, all the female characters perish at the end. Molly goes away, Linda becomes a computer construct and Jane and all the others die. In Neuromancer, we see all the female characters perishing. And what could be the possible reason? Because they had crossed patriarchy? Gibson certainly seems to be an agent of patriarchy when he carefully makes his girls strong and commanding and in the end throws them to hell fire because they have crossed patriarchy. Lastly, the AIs or the Artificial Intelligences seem masculine and patriarchal. Though being AIs, they are out of the question of gender because as machines they have no gender but for one thing Wintermute never takes control of a girl, he always appears with the help of Armitage or The Finn. Even the computer construct Wintermute steals Dixie Flatline who is a male. So Wintermute is constantly referred to as a he not a she. Even the other half Neuromancer resurrects Linda Lee but only to lure Case into the Matrix. When the two are united, together they become or take control of the Matrix, a patriarchal masculine trait to conquer and control everything. Not to mention the feminized place the Matrix. The meaning of matrix is "the womb", where all the cowboys "jack in", which becomes a unity of two genders and the cowboys being in the active position. Neuromancer and Wintermute together taking control of the Matrix means conquering the feminine land, just like America, which before it was conquered was the virgin land. Cyberspace is not only a subversive place for women but also for "lesser” males. The console cowboys of Gibson's world are computer hackers but in real life they would be known as "nerds". So the real life nerds had been given a masculine makeover. With the name itself "cowboy", masculinity has been endowed with power. With all the knowledge and technology, masculinity has been allotted to Case. With all the cuts and bruises that have been inflicted on Case and his constant drug addiction, he seems to be a cowboy right out of a Hollywood "guy" film. Masculinity is thus a 
burden on males too because it's a constant attempt to act masculine. Like gender performativity techno-masculinity or masculinity is constructed because it depends on props.

\section{Techno-fetishism}

According to Laura Mulvey in her essay "Visual Pleasure and Narrative Cinema", a female body is fetishized to create a disavowal from the castration complex. Disavowal is an act where the fetish diverts the attention of the viewer from the castration anxiety towards that fetish. In this age of technology, there is also techno-fetishism. For females, the fetish appears in two ways either by showing hyper-femininity or by being an action girl just like Molly. Hyper-femininity is the act of being excessively feminine by wearing extensive make-up with typically girlish attitudes. Also in the techno-age, there is fetishization of masculinity. Cyborg being without gender has necessitated the fetishizing the body because the cyborg body is a lack. As patriarchy feels that there is a need to fix gender so the technique of fetishization is applied to hide the lack. Thus masculine fetishization also works in two ways: showing off hyper-masculinity like in the Terminator movies where Arnold Schwarzenegger is the lack and that lack is disavowed by displaying hyper-masculinity. Also by creating a disavowal through technology like our console cowboy Case the disavowal is created. As Case has been portrayed as the follower not the action-taker, he might be suffering from an identity crisis or he seems to have been castrated. For Case, the thrill of the cyberspace is everything and for that fixed position of masculinity he wanted to escape the physical: "In the bars he'd frequented as a cowboy hotshot, the elite stance involved a certain relaxed contempt for the flesh. The body was meat” (Gibson, 1984, p. 8). Case's indomitable urge to be the one with matrix creates the fetish and a disavowal is created through the cyberspace and drugs. As drugs and cyberspace create the disavowal from the castration complex, it is also female empowerment, which is disavowed.

In Neuromancer, there is another place where patriarchy dwells and that is the Zion of the Rastafarians. Though the Zionists look up to Molly as a hero, all of Zion is male inhibited. People would argue that it is the culture of the Rastafarians but there is a reason why Maelcum helps Case. Being a patriarchal culture the Rastafarian Maelcum decides to help Case not Molly. Maelcum becomes a patriarchal male sidekick for Case as he helps him to learn the ways of the patriarchy.

\section{Conclusion}

Haraway foresaw a Utopia in the dystopian future-possibly a "Cyborgian Utopia", because she along with many others believed that cyborg will create a new era for women, melting the stereotypical gender roles. But as we became data bodies the information emitting from our bodies gives rise to new kinds of politics. Patriarchy is that hegemonic structure which uses the information to dominate the women. So why was so much hope put on the emergence of a genderless entity? Is it only because if it has does not have any gender, it will be able to escape gender politics? Patriarchy uses the information of this information age to reinscribe the bodies with the information of gender. Thus the body of the cyborg can also be gendered. Even when we log into the cyberspace we need a gendered identity. So it is not that easy to go usher in a genderless future.

It is evident that even in the landmark work of Neuromancer, where the central character is apparently a woman, also a cyborg, with dangerous attributes to kill and rise, is also not above the gender politics. Rather, in an apparently female-oriented background, we see the complete opposite, which has been referred and pointed in this paper. In the science fiction like the Neuromancer, the idea of cyborg alleviates the politics of gender it 
also at the same time alleviates the human capacity of love and affection. So a cyborg whose gender roles are fluid, is more of a machine, devoid of any humane capacity, only with bionic attributes to win. Hence, the question of empowering the woman in a form of cyborg, according to us, is rather disrespectful than courageous. So rather than liberating women, this SF somehow celebrates the age-old stereotypical form of patriarchy that proves Haraway’s "Manifesto" quite invalid.

\section{References}

Althusser, L. (1989). Ideology and ideological state apparatuses. In Lenin and philosophy and other essays (pp. 86-170). London: New Left Books.

Aronson, P. (2003). Feminist or “postfeminist”?: Young women’s attitude toward feminism and gender relation. Gender \& Society, 17(6), 903-922. New York: Sage Publications Inc.

Bordo, S. (1999). Beauty (re)discovers the male body. In The male body (pp. 168-225). New York: Farrar, Straus and Giroux.

Bray, A., \& Colebrook, C. (1998). The haunted flesh: Corporeal feminism and the politics of (dis)embodiment. Chicago Journals, 24(1), 35-67. Chicago: The University of Chicago Press.

Bredehoft, T. A. (1995). The Gibson Continuum: Cyberspace and Gibson’s Mervyn Kihn Stories. Science Fiction Studies, 22(66), Part 2. Indiana: SF-TH Inc.

Brians, P. (1984). Study guide for William Gibson: Neuromancer. Retrieved from https://www.wsu.edu/ brians/science_fiction/neuromancer.html

Butler, J. (1993). Bodies that matter: On the discursive limits of "sex". New York: Routledge.

Cherniavsky, E. (1993). (En)gendering cyberspace in Neuromancer: Postmodern subjectivity and virtual motherhood. Genders, 18, 32-46.

Csicsery-Ronay, Jr., I. (1992). The sentimental futurist: Cybernetics and art in William Gibson’s Neuromancer. Critique: Studies in Contemporary Fiction, 33(3), 221-240.

Daniels, J. (2009). Rethinking cyberfeminism(s): Race gender and embodiment. Women's Studies Quarterly, 37(1/2), 101-124. The Feminist Press at the University of New York.

Davidson, C. (1996). Riviera's golem, Haraway's cyborg: Reading Neuromancer as Baudrillard's simulation of crisis. Science-Fiction Studies, 23(2), 188-198. Indiana: SF-TH Inc.

Fernbach, A. (2000). The fetishization of masculinity in science fiction: The cyborg and the console cowboy. Science Fiction Studies, 27(2), 234-255. Indiana: SF-TH Inc.

Gibson, W. (1984). Neuromancer. New York: Berkley Publishing Group.

Grant, G. (1990). Transcendence through detournement in William Gibson’s Neuromancer. Science-Fiction Studies, 17(1), 41-49. Indiana: SF-TH Inc.

Hall, S. (1990). Encoding decoding. In Culture, media, language. London: Unwin Hyman.

Hall, E. J., \& Rodriguez, M. S. (2003). The myth of postfeminism. Gender \& Society, 17(6). New York: Sage Publications Inc.

Haraway, D. (1991). A cyborg manifesto: Science, technology, and socialist-feminism in the late twentieth century. In Simians, Cyborgs and Women: The Reinvention of Nature (pp. 149-181). New York: Routledge.

Hollinger, V. (July, 1994). Utopia, postmodernism, and feminism: A triology of significant works. Retrieved From http://www.depauw.edu/sfs/review_essays/holl63.htm

Huntington, J. (1990). Newness, neuromancer, and the end of narrative. Essays and Studies, 43, 59-75.

Lancashire, I. (2003). Ninsei street, Chiba city. In Gibson's Neuromancer. Science Fiction Studies, 30(2), 341-346. Social Science Fiction. Indiana: SF-TH Inc.

Lanza, J. (1992). Female Rollercoasters (And other virtual vortices). Performing Arts Journal, 14(2), 51-63. Cambridge, MA: Performing Arts Journal, Inc.

Leblanc, L. (n.d.). Razor girls: Genre and gender in cyberpunk fiction. Retrieved From http://project.cyberpunk.ru/idb/genre_and_gender_in_cyberpunk_fiction.html

Myers, T. (2001). The postmodern imaginary in William Gibson's Neuromancer. Modern Fiction Studies, 47(4), 887-909.

Nakamura, L. (2002). Cybertypes: Race, ethnicity and identity on the internet. New York: Routledge.

Plant, S. (1997). Zeroes + ones: Digital women and the new technoculture. London: Fourth Estate.

Shaye, R. (Producer), \& Craven, Wes (Director). (1984). A nightmare on elm street. Los Angeles: New Line Cinema. 
Stevens, T. (1996). "Sinister fruitiness": "Neuromancer” internet sexuality and the Turing test. Studies in the Novel, 28(3), 414-433.

Tillett, W. (2008). Dreaming of Molly Millions, the panther moderns and body hacking. Retrieved from http://transreal.org/2008/07/11/dreaming-of-molly-millions-the-panther-moderns-and-body-hacking/

Wilson, J. (n.d.). Of Machines and meat: Cyberpunk, the postmodern condition and a posthuman reality. Retrieved from http://www.athabascau.ca/courses/engl/491/wilson.pdf

Zwaan, V. de. (1997). Rethinking the slipstream: Kathy Acker reads Neuromancer. Science-Fiction Studies, 24(3), 459-470. Indiana: SF-TH Inc. 